\title{
RESENHA DA OBRA INTERNATIONAL LAW FOR HUMANKIND: TOWARDS A NEW JUS GENTIUM, DE ANTÔNIO A. CANÇADO TRINDADE
}

Paula Wojcikiewicz Almeida

REVIEW OF THE BOOK INTERNATIONAL LAW FOR HUMANKIND: TOWARDS A NEW JUS GENTIUM, BY ANTONNIO A. CANÇADO TRINDADE

\section{RESENHA}

A. A. CANÇADO TRINDADE. INTERNATIONAL LAW FOR Humankind: Towards a NeW Jus Gentium. Martinus NiJHOFF Publishers, 2010.

$I$ nternational Law for Humankind: Towards a New Jus Gentium intitula-se o primeiro Curso Geral de Direito Internacional Público ministrado por um jurista brasileiro desde a fundação da Academia de Direito Internacional da Haia em 1923. Os Cursos Gerais são ministrados por acadêmicos de grande experiência e notoriedade. Tratam com profundidade da evolução e das tendências do Direito Internacional, abordando os grandes eixos da matéria segundo os quais é estruturado o pensamento jurídico. O professor e juiz da Corte Internacional de Justiça, Antônio Augusto
Cançado Trindade, brinda a Academia de Direito Internacional da Haia com seu Curso Geral de Direito Internacional Público, ministrado entre julho e agosto de 2005, cuja versão abreviada é ora comentada. ${ }^{1}$

A presente obra possui extrema relevância no contexto dos escritos nacionais e internacionais sobre o tema, buscando ultrapassar a visão interestatal e voluntarista do Direito Internacional, predominante nos dias atuais, ${ }^{2}$ para resgatar o primado da razão da humanidade sobre a razão de Estado, constante do pensamento dos pais fundadores dos séculos XVI e 
XVII, como F. de Vitoria (Relecciones Teológicas, 1538-1539), F. Suárez (De Legibus ac Deo Legislatore, 1612), A. Gentili (De Jure Belli, 1598), H. Grotius (De Jure Belli ac Pacis, 1625), S. Pufendorf (De Jure Naturae et Gentium, 1672) e C. Wolff (Jus Gentium Methodo Scientifica Pertractatum, 1749), dentre outros. ${ }^{3}$ Trata-se de um marco na doutrina brasileira e internacional, pois a tradição jusnaturalista do Direito Internacional, apesar de nunca ter desaparecido, havia sido sufocada pelo positivismo voluntarista. A obra marca, portanto, o renascimento contínuo do direito natural, valorizando a concepção universalista do Direito Internacional no mundo de hoje, tal qual presente no ideal dos pais fundadores da disciplina. Cançado Trindade reconhece que, apesar de o mundo contemporâneo ser distinto da época na qual foram redigidos os escritos dos pais fundadores, “(...) a aspiração humana permanece a mesma, qual seja, a da construção de um ordenamento internacional aplicável tanto aos Estados (e organizações internacionais) quanto aos indivíduos, consoante certos padrões de justiça”. ${ }^{4}$

A obra é composta por textos selecionados e atualizados por Cançado Trindade, redigidos no período de 1999 a 2005, que resultam de ensinamentos ministrados pelo autor ao longo das últimas três décadas. É, portanto, fruto de reflexões pessoais acumuladas durante toda uma vida dedicada à teoria e prática do Direito Internacional. Cançado Trindade dirige-se, de forma positiva e confiante, às futuras gerações de juristas internacionalistas, atentos para as aspirações da comunidade internacional nos tempos atuais. Figura como leitmotiv da presente obra a constatação de que o Direito Internacional é um corpus juris orientado para atingir as necessidades e aspirações dos seres humanos e da humanidade de modo geral. A compreensão de seu substrato é essencial para sua correta abordagem. O autor adverte: não se trata de um manual de Direito Internacional, mas sim de uma obra crítica que transcende o direito positivo, reunindo temas selecionados e apresentados de acordo com o leitmotiv que a permeia. $\mathrm{O}$ autor se preocupa em restaurar valores em um momento de evidente crise e negligência dos mesmos e confia, para tanto, no papel de um Direito Internacional universalista e humanizado, fiel ao pensamento dos pais fundadores da disciplina e às necessidades da comunidade internacional.

Parte-se do pressuposto de que a dimensão puramente estatal do Direito Internacional afigura-se ultrapassada e que a personalidade jurídica internacional foi expandida para reconhecer como sujeitos não apenas as organizações internacionais, mas também os indivíduos. O novo jus gentium deste início do século XXI ou Direito Internacional para a humanidade, consoante a recta ratio, ${ }^{5}$ assenta-se obrigatoriamente sobre essas bases, centrando-se nas aspirações e necessidades legítimas da humanidade civitas maxima gentium. ${ }^{6}$

A obra é composta de oito partes, que se encadeiam logicamente com vistas à construção de um novo jus gentium. 
Cançado Trindade inicia suas considerações em um capítulo preliminar no qual apresenta uma sólida análise acerca das bases necessárias para a compreensão do novo Direito Internacional para a Humanidade, traçando sua evolução histórica. A construção doutrinária valoriza e resgata o legado dos escritos dos pais fundadores do Direito Internacional nos séculos XVI e XVII, sobretudo F. de Vitoria, F. Suárez e H. Grotius, além de A. Gentilli e S. Pufendorf, que sustentavam o ideal de uma civitas maxima regida pelo direito das gentes. ${ }^{7}$

Em seguida, Cançado Trindade adentra na identificação das características básicas do novo jus gentium, capaz de atingir as necessidades e aspirações da humanidade, que marca o início do século XXI. Sua característica básica principal consiste no reconhecimento de que a ordem jurídica internacional ultrapassou a ótica puramente interestatal para abarcar igualmente indivíduos, organizações não governamentais e outras entidades da sociedade civil, além de Estados e organizações internacionais. Não se trata de uma concepção nova, pois o jus gentium clássico já abarcava, em sua evolução histórica, a humanidade como um todo, não se limitando à ótica interestatal. Segundo o autor, o jus gentium atual possui a finalidade de resgatar o ideal de universalidade presente no pensamento dos pais fundadores do droit des gens, de onde extrai suas raízes mais profundas. A concepção universalista do Direito Internacional considera que os Estados não foram originalmente concebidos como sujeitos exclusivos do Direito Internacional. Para Cançado Trindade, as fundações do novo jus gentium são, portanto, independentes da vontade estatal, pois derivam da consciência universal, do sentimento de justiça e de bases éticas, incorporando valores humanos essenciais, que prevalecem com relação à raison d'Etat. O novo jus gentium, atualmente caracterizado como sendo o Direito Internacional para a humanidade, é assim imbuído de uma dimensão temporal com o objetivo de adaptar-se progressivamente às necessidades e aspirações da humanidade.

A segunda parte da obra abarca as fundações do Direito Internacional, remetendo ao papel e à importância dos princípios básicos da disciplina, que formam o substrato da própria ordem jurídica. Como uma manifestação da consciência jurídica internacional, fonte material por excelência do Direito Internacional nas palavras de Cançado Trindade, os princípios do Direito Internacional inspiram o processo de adoção, interpretação e aplicação das normas jurídicas. De acordo com o autor, os princípios gerais do direito fornecem os próprios fundamentos do Direito Internacional Público e, por isso, não deveriam ser negligenciados pela doutrina contemporânea. ${ }^{8} \mathrm{O}$ reconhecimento do papel fundamental dos princípios conduz ao reconhecimento de princípios considerados indispensáveis, como o jus cogens, que traduz a ideia de uma justiça objetiva. ${ }^{9}$ Cançado Trindade sustenta a importância dos princípios, que permeiam o sistema jurídico e transcendem o direito positivo internacional. Eles refletem a idée de droit e a idée de justice. 
A partir de tais considerações, o autor afirma a validade permanente dos princípios gerais do Direito Internacional que conformam a aplicação de suas normas, como o princípio fundamental da proibição do uso da força, previsto no artigo 2 (4) da Carta da ONU. A validade contínua de tal princípio reafirma a primazia do Direito Internacional sobre a força, conforme exposto no capítulo IV da segunda parte da presente obra, ${ }^{10}$ tendo em vista as inúmeras tentativas de desconstrução do Direito Internacional nos tempos atuais em situações que envolvem o uso da força fora dos parâmetros estabelecidos pela Carta da ONU.

A terceira parte da obra adentra na formação do Direito Internacional, reavaliando a teoria das fontes formais do Direito Internacional para demonstrar seu caráter não exaustivo e sua insuficiência nos tempos atuais. ${ }^{11}$ Cançado Trindade sinaliza que a formação do Direito Internacional contemporâneo não pode se restringir unicamente às fontes formais, o que decorreria de um positivismo analítico anacrônico, mas deve buscar sua legitimidade - opinio juris communis - no atendimento do interesse público e na realização das necessidades da comunidade internacional como um todo. ${ }^{12}$ Isso porque o novo jus gentium emana da consciência jurídica universal e transcende a vontade dos Estados enquanto sujeitos de Direito Internacional. Assim sendo, o autor sustenta que as fontes formais do Direito Internacional devem ser analisadas conjuntamente com a fonte material do Direito Internacional por excelência, qual seja, a consciência jurídica universal ou communis opinio júris. ${ }^{13}$ Cançado Trindade identifica manifestações da consciência jurídica universal no direito dos tratados, na cláusula Martens, na jurisprudência internacional e nas resoluções da ONU.

Os sujeitos de Direito Internacional são abordados na quarta parte da obra, que tem como objetivo demonstrar a existência de um processo de humanização do Direito Internacional, repercutindo na expansão da personalidade jurídica internacional. Para Cançado Trindade, a inquestionável expansão da personalidade jurídica internacional caracteriza o novo jus gentium. O fenômeno do surgimento das organizações internacionais determinou o fim do monopólio do Estado, alterando globalmente a estrutura do Direito Internacional. Além das organizações internacionais, o autor resgata a condição da pessoa humana como sujeito de Direito Interno e Internacional (e não apenas na qualidade de ator), na linha do pensamento jurídico internacional da segunda metade do século XX e do processo de humanização do Direito Internacional contemporâneo. ${ }^{14}$ Cançado Trindade denuncia a doutrina positivista clássica e sustenta que os indivíduos são indiscutivelmente sujeitos de direitos e obrigações que emanam diretamente do Direito Internacional, exercendo um papel fundamental no processo de formação da communis opinio juris. São eles os destinatários primordiais das normas jurídicas internacionais e nacionais. ${ }^{15}$ Segundo o autor, o reconhecimento da personalidade jurídica internacional - 
ativa e passiva - dos indivíduos caminha paralelamente com o necessário reconhecimento de sua capacidade jurídica para reivindicar direitos no plano internacional. ${ }^{16}$ Tais considerações conduzem naturalmente ao acesso direto lato sensu à justiça internacional - droit au Droit por meio do direito de petição individual no nível internacional (jus standi) e do direito à realização da justiça no nível internacional. ${ }^{17}$ Com efeito, o direito de acesso à justiça lato sensu traduz o direito a uma ordem jurídica capaz de proteger efetivamente os direitos fundamentais da pessoa humana. ${ }^{18}$ Marca, como sustenta o autor, a emancipação do indivíduo com relação a seu próprio Estado e a primazia da raison de l'humanité perante a raison d'État. Constitui, para Cançado Trindade, o mais importante legado do pensamento jurídico internacional da segunda metade do século XX. ${ }^{19}$ Além dos indivíduos, a humanidade é igualmente considerada como sendo um sujeito de Direito Internacional, pois permeia o corpus juris da disciplina. A dificuldade reside na construção conceitual de representação legal de humanidade que leva à consolidação da capacidade jurídica internacional.

$\mathrm{Na}$ quinta parte da obra, Cançado Trindade busca construir o Direito Internacional para a Humanidade, o novo jus gentium, partindo de construções conceituais em curso que reafirmam seu caráter universal. Trata-se de reconhecer, como sublinha o autor, a emergência de considerações relativas à ordem pública, que se refletem nas construções conceituais das normas imperativas do direito internacional em geral, dos direitos fundamentais inderrogáveis e das obrigações erga omnes de proteção em sua dupla dimensão. Para Cançado Trindade, os conceitos de jus cogens e de obrigações erga omnes de proteção - horizontais e verticais - já integram o universo conceitual do Direito Internacional, na linha da visão universal do droit des gens proposta pelos pais fundadores da disciplina. O conceito de jus cogens, que transcende o domínio do direito dos tratados para abarcar, dentre outros, a responsabilidade internacional dos Estados, é considerado pelo autor como um dos pilares do novo jus gentium. Além do jus cogens, são citados outros conceitos que também emergem do novo jus gentium do início do século XXI, como sendo fruto da consciência jurídica universal. Tais construções conceituais acabam por reconhecer as limitações dos Estados no que tange ao atendimento das necessidades e aspirações da humanidade. Dentre as construções conceituais abordadas pelo autor, figura a responsabilidade estatal por crimes internacionais e a jurisdição universal. Em seu âmbito, verifica-se em jurisprudência recente a complementaridade entre a responsabilidade internacional dos Estados e a responsabilidade dos indivíduos por crimes internacionais. ${ }^{20}$ Salienta que o princípio da jurisdição universal, que ultrapassa as fronteiras da territorialidade e da nacionalidade, já traz em si mesmo a ideia da complementaridade e da existência de interesses fundamentais que devem ser protegidos pela comunidade internacional. 
Cançado Trindade resgata, na sexta parte da obra, considerações básicas de humanidade que fornecem ilustrações acerca da emergência de um novo jus gentium, em diversas áreas do Direito Internacional. Tais considerações básicas são indispensáveis no momento atual, marcado por uma crise profunda de valores, e já se encontram no corpus juris do Direito Internacional contemporâneo. Estão presentes nos instrumentos de Direito Internacional contemporâneo, na jurisprudência internacional e na doutrina internacional considerada lúcida pelo autor. Merecem, segundo ele, maior atenção e cultivo pela doutrina internacionalista com vistas à construção de um novo jus gentium, que resgata a posição central do ser humano e da humanidade. Dentre os capítulos do Direito Internacional nos quais as considerações básicas de humanidade se fazem presentes, especial atenção é dada a temas como desarmamento, direito dos tratados, responsabilidade de Estados, sucessão de Estados, território, direito diplomático e consular e, finalmente, convergências entre as três vertentes de proteção da pessoa humana, quais sejam, o Direito Internacional dos Direitos Humanos, do Direito Internacional Humanitário e do Direito Internacional dos Refugiados. ${ }^{21}$

De suma importância é a sétima parte da obra, que avalia o estado atual e as perspectivas de solução pacífica de controvérsias, reiterando a necessidade de uma jurisdição compulsória. ${ }^{22}$ Cançado Trindade cita diversos meios complementares de solução pacífica das controvérsias, destacando a desnecessidade de esgotamento das possibilidades de negociação antes do recurso a outros meios de solução pacífica. Sublinha a ambivalência entre o princípio da solução pacífica das controvérsias previsto na Carta da ONU e a prerrogativa das partes em disputa no sentido de adotar os mecanismos de solução pacífica livremente. Tal ambivalência conduz à vulnerabilidade da solução das controvérsias internacionais, que ficam sujeitas ao voluntarismo estatal. Reitera o autor que os meios de solução pacífica não se limitam ao voluntarismo estatal, fornecendo exemplos que ilustram tal tese. Com efeito, há atualmente uma flagrante diminuição da liberdade de escolha acerca dos meios de solução pacífica das controvérsias internacionais à disposição dos Estados. Isso ocorre em função de previsões em tratados multilaterais dispondo acerca dos mecanismos a serem obrigatoriamente utilizados. É que os mecanismos de solução pacífica das controvérsias internacionais transcendem os interesses dos Estados em questão, envolvem interesses gerais da comunidade internacional e devem ser analisados sob essa ótica. Tendo em vista tais considerações, Cançado Trindade conclui que qualquer estudo sobre o assunto deverá partir, prioritariamente, do princípio geral da solução pacífica das controvérsias internacionais para, então, avaliar a livre escolha das partes no que tange aos meios, que consiste em simples prerrogativa. Nessa linha, o autor lembra o antigo ideal da jurisdição compulsória como uma manifestação da busca da comunidade 
internacional pela realização da justiça no nível internacional.

Cançado Trindade destaca o fato de que a cláusula facultativa de jurisdição obrigatória, presente nos estatutos da Corte Permanente de Justiça Internacional e da Corte Internacional de Justiça, foi resultado da iniciativa do jurista brasileiro Raul Fernandes, que pretendia encontrar um equilíbrio para o impasse ocorrido no seio do comitê de juristas de 1920. Tal cláusula teve inicialmente repercussão positiva, sofrendo posterior declínio sob a égide da Corte Internacional de Justiça. O autor resgata os travaux préparatoires para sublinhar o uso distorcido da cláusula por diversos Estados, o que retirou sua eficácia e esvaziou sua finalidade. Isso porque a elaboração do estatuto da Corte Internacional de Justiça não levou em consideração os progressos da comunidade internacional, refletindo a concepção voluntarista do Direito Internacional dos anos 1920, marcada por uma dimensão puramente interestatal. Para Cançado Trindade, tal concepção não mais se coaduna com o Direito Internacional contemporâneo. Para sustentar tal tese, recorre à experiência da Corte Interamericana de Direitos Humanos e da Corte europeia de Direitos Humanos, cujas cláusulas facultativas de jurisdição obrigatória, reconhecidas como sendo cláusulas pétreas, não admitem outras limitações além daquelas expressamente previstas nos tratados de Direitos Humanos em questão. Por esse motivo, sustenta que a inserção de reservas ou limitações nas cláusulas facultativas de jurisdição obrigatória, apesar de não ser expressamente proibida, representa uma distorção da concepção original encontrada nos referidos travaux préparatoires.

Cançado Trindade anuncia: "the time has come to overcome definitely the regrettable lack of automatism of the international jurisdiction" (p. 581). Reconhece que apesar dos avanços ocorridos na área do Direito Internacional dos Direitos Humanos, ainda existem importantes resistências na esfera interestatal para a aceitação do ideal da jurisdição obrigatória, que reflete a necessidade da comunidade internacional atualmente. ${ }^{23}$ Entretanto, considera que algumas resistências já foram vencidas como demonstra a experiência do Tribunal de Justiça da União Europeia; da Corte Europeia de Direitos Humanos após a entrada em vigor do Protocolo n. 11; do Tribunal Penal Internacional; e da Convenção das Nações Unidas sobre o Direito do Mar de 1982. O autor fornece tais exemplos para demonstrar que a ideia de jurisdição compulsória já está presente em algumas áreas do Direito Internacional, sendo uma manifestação do reconhecimento de que a ótica voluntarista encontra-se ultrapassada. Corrobora tal afirmação o fato de que diversos tratados internacionais preveem cláusulas compromissórias estabelecendo o recurso obrigatório à jurisdição da Corte Internacional de Justiça para a solução das controvérsias atinentes à sua interpretação e aplicação. Cançado Trindade sugere que uma inclusão sistemática de cláusulas compromissórias no âmbito de tratados internacionais contribuiria para expandir o escopo da jurisdição compulsória. 
Na mesma linha, o autor sublinha o caráter positivo da multiplicidade de tribunais internacionais no Direito Internacional contemporâneo, o que indica uma expansão da jurisdição internacional, conjuntamente com o processo de descentralização da ordem jurídica internacional para além da ótica puramente interestatal. ${ }^{24} \mathrm{O}$ processo de "jurisdicionalização" do Direito Internacional reforça a primazia do Direito Internacional sobre a força, confortando o jusinternacionalista sensato. De fato, Cançado Trindade vê com bons olhos o fenômeno da multiplicação dos tribunais internacionais. O referido fenômeno (i) reflete uma necessidade da comunidade internacional contemporânea, (ii) contribui para o antigo ideal de realização da justiça internacional, e (iii) reafirma a posição dos indivíduos como sujeitos de Direito Internacional. Tais considerações corroboram o processo histórico de humanização do Direito Internacional, conducente ao novo jus gentium.

Para o autor, a função jurisdicional é guiada, sobretudo, pelo ideal de realização da justiça, ${ }^{25}$ que não constitui uma noção abstrata. Ora, não é possível julgar casos envolvendo violações graves dos direitos humanos e do direito internacional humanitário sem atentar para os valores humanos fundamentais, já que o direito e a ética são indissociáveis, contrariamente aos postulados da doutrina positivista. ${ }^{26}$ Um tribunal internacional não pode permanecer indiferente ao sofrimento humano, privilegiando a raison d'État e denegando justiça aos indivíduos sob sua jurisdição. Cançado Trindade afirma que "a busca da justiça deve ser preservada como objetivo último; assegurar justiça às vítimas compreende, inter alia, permitir que elas possam buscar e obter justiça pelos crimes sofridos". ${ }^{27}$ Contrariamente ao positivismo formalista presente em grande parte dos julgados da Corte Internacional de Justiça, ${ }^{28}$ o autor adere a uma visão principista tendente a aplicar um direito internacional evolutivo e atento aos valores da humanidade, na busca da realização da justiça. ${ }^{29}$

A última parte da obra anuncia as perspectivas para o futuro. Cançado Trindade retoma o legado do ciclo das Conferencias Mundiais das Nações Unidas ao longo dos anos 1990 até o ano de 2001. As Conferências contribuíram para desenhar a agenda social internacional do início do século XXI, em consonância com as preocupações do Direito Internacional contemporâneo e com as aspirações da comunidade internacional. Analisa o exercício da codificação e o progressivo desenvolvimento do Direito Internacional na perspectiva histórica, além de trazer lições e projeções para o futuro. Pondera que o processo de codificação é guiado por necessidades jurídicas da comunidade internacional (e não apenas dos Estados) que evoluem através dos tempos e, por esse motivo, tende a ser complexo, dinâmico e multifacetado. A codificação e o desenvolvimento progressivo do Direito Internacional caminham pari passu, apontando para a universalização do Direito Internacional. $\mathrm{O}$ autor insiste que o Direito Internacional contemporâneo não pode mais confinar-se nos rígidos 
postulados do Direito Internacional convencional tradicional, devendo ser dotado de um corpus juris objetivo e dar expressão à opinio juris communis emanada da consciência jurídica universal.

Cançado Trindade fundamenta-se em quantidade expressiva de referências bibliográficas e jurisprudenciais direta e indiretamente relacionadas ao Direito Internacional em mais de 50 páginas, o que enriquece sobremaneira o presente livro. As obras e os casos jurisprudenciais foram cuidadosamente selecionados e organizados de acordo com as partes e capítulos do livro, de forma a facilitar ao leitor o aprofundamento dos temas considerados mais relevantes. $\mathrm{O}$ amor à disciplina e o zelo com os leitores e discípulos transparecem e perpassam toda a obra, o que a torna sensivelmente humanizada. "There is reason for hope and confidence in the future of international Law", assegura Cançado Trindade em seu epílogo. A mensagem de confiança deixada pelo autor em sua obra merece ser retomada: as novas gerações de juristas internacionalistas devem fomentar a revitalização das fundações e princípios básicos do Direito Internacional contemporâneo, testemunhando a expansão da personalidade jurídica internacional, com a primazia do Direito Internacional sobre a força, na busca da realização da justiça com o objetivo de deixar um mundo melhor para nossos descendentes. Segundo Cançado Trindade, os saltos qualitativos na evolução do jus gentium são alcançados em momentos de crise, como testemunha o desenvolvimento histórico do Direito Internacional. ${ }^{30}$
Conclui sua obra atualíssima demonstrando um profundo sentimento de confiança na nova geração de juristas internacionalistas para a construção do novo jus gentium desse novo século.

Trata-se de uma obra indubitavelmente perene, fruto das reflexões pessoais de Cançado Trindade acumuladas nas últimas três décadas, como acadêmico e juiz internacional, que resgata e dá vida à consciência jurídica universal, construindo um novo jus gentium para a humanidade. A obra é desenvolvida em torno de postulados que se articulam conforme seu leitmotiv - o Direito Internacional é um corpus juris orientado para atingir as necessidades e aspirações dos seres humanos e da humanidade - e flui de forma crítica e positiva, trazendo uma mensagem de confiança e esperança nas gerações futuras. Como latino-americanos e brasileiros, orgulhamo-nos de ter entre nós o professor e juiz Antônio Augusto Cançado Trindade, o primeiro jusinternacionalista brasileiro a ministrar o Curso Geral de Direito Internacional Público desde a fundação da Academia de Direito Internacional da Haia. International Law for Humankind: Towards a New Jus Gentium é uma obra que não merece reparos em função de sua qualidade excepcional e constitui uma contribuição valiosíssima para o estudo do Direito Internacional, sendo, portanto, indispensável para todos aqueles que pretenderem obter uma visão lúcida do Direito Internacional contemporâneo, que leva em conta as necessidades e aspirações da humanidade, sem ignorar a carga histórica propugnada pelos pais fundadores e, sobretudo, sem correr o risco de confundir-se com visões 
míopes tão presentes em momentos de crise de valores. É de leitura obrigatória para uma geração de juristas internacionalistas guiada por valores, que é capaz de enxergar o ser humano para além das amarras da soberania estatal e de resgatar sua posição central enquanto sujeito de direito interno e internacional.

\section{NOTAS}

1 O texto original do Curso Geral de Direito Internacional ministrado pelo professor Antônio Augusto Cançado Trindade foi publicado no Recueil des Cours da Academia da Haia em 2005: A. A. CANÇADO TRINDADE, International Law for Humankind: Towards a New Jus Gentium - General Course on Public International Law - Part I, 316 Recueil des Cours de l'Académie de Droit International de la Haye, 2005; International Law for Humankind: Towards a New Jus Gentium - General Course on Public International Law - Part II, 317 Recueil des Cours de l'Académie de Droit International de la Haye, 2005.

2 A corrente doutrinária que conduzia à personificação do Estado no Direito Internacional inspirou-se, sobretudo na filosofia do direito de Hegel, que acabou por influenciar a evolução do Direito Internacional no final do século XIX e no início do século XX. Segundo Cançado Trindade, “as Universidades não só brasileiras como de tantos outros países, encontram-se hoje infestadas de positivistas e realistas, o que explica o preocupante declínio no cultivo da ciência jurídica e das ciências sociais", in A. A. CANÇADO TRINDADE, A Humanização do Direito Internacional, Belo Horizonte, Ed. Del Rey, 2006, p. 21.

3 Association Internationale Vitoria-Suarez, Vitoria et Suarez - Contribution des Théologiens au Droit International Moderne, éd. Pédone, Paris, 1939, pp. 169. 170; LAUTERPACHT (H.), "The Grotian Tradition in International Law", 23 British Yearbook of International Law, 1946, pp. 1-53; et V. P. GUGGENHEIM, “Contribution à l'histoire des sources du droit des gens, 94 Recueil des Cours de l'Académie de Droit International de La Haye, 1958, pp. 21-25.
4 A. A. CANÇADO TRINDADE, A Humanização do Direito Internacional, op. cit., p. 14.

5 Para maiores detalhes acerca da relação entre a recta ratio e o jus gentium, vide A. A. CANÇADO TRINDADE, A Humanização do Direito Internacional, op. cit., pp. 6-16.

6 O autor lista desenvolvimentos recentes do Direito Internacional que demonstram a preocupação com os seres humanos, como a existência de áreas do Direito Internacional voltadas para a proteção dos Direitos Humanos; a invocação da 'humanidade' em tratados internacionais; a construção jurisprudencial de tribunais internacionais contemporâneos que leva em consideração preocupações de seres humanos e humanidade; e a prática de Estados e organizações internacionais e outros sujeitos de Direito Internacional que leva em consideração as necessidades e aspirações dos seres humanos e humanidade como um todo.

7 Vide A. A. CANÇADO TRINDADE, A Humanização do Direito Internacional, op. cit., pp. 8-16.

8 Vide Corte IDH, Condição Jurídica e os Direitos dos Migrantes Indocumentados, 2003, Voto concordante do juiz A. A. CANÇADO TRINDADE no parecer n. 18, par. 44 e 46.

9 A. A. CANÇADO TRINDADE, El Derecho Internacional de los Derechos Humanos en el siglo XXI, Editorial Jurídica de Chile, 2001, pp. 416-429; A. A. CANÇADO TRINDADE, El ejercicio de la función judicial internacional Memorias de la Corte Interamericana de Derechos Humanos, Belo 
Horizonte, ed. Del Rey, 2011, pp. 73-83 e 127-132; A. A. CANCADO TRINDADE, Évolution du droit international au droit des gens - l'accès des individus à la justice internationale : le regard d'un juge, Paris, ed. Pedone, 2008, pp. 126-129.

10 Vide A. A. CANÇADO TRINDADE, A Humanização do Direito Internacional, op. cit., pp. 175-193.

11 Ibid, pp. 30-96; A. A. CANÇADO TRINDADE, $O$ Direito Internacional em um mundo em transformação, Rio de Janeiro, ed. Renovar, 2002, pp. 19-76.

12 Corte IDH, Haitianos e Dominicanos de Origem Haitiana na República Dominicana, Medidas Provisórias de Proteção, 2000, Voto concordante do juiz A. A. CANÇADO TRINDADE, par. 12; Corte IDH, Bámaca Velasquez versus Guatemala, 25 de novembro de 2000, Explicação de Voto do juiz A. A. CANÇADO TRINDADE na sentença sobre o mérito, par. 28 e 16 .

13 Corte IDH, Condição Jurídica e os Direitos dos Migrantes Indocumentados, 2003, Voto concordante do juiz A. A. CANÇADO TRINDADE no parecer n. 18, pars. 23-25 e 28-30.

14 Vide A. A. CANÇADO TRINDADE, "Las Cláusulas Pétreas de Protección Internacional del Ser Humano: El Acceso Directo de los Individuos a la Justicia a Nivel Internacional y la Intangibilidad de la Jurisdicción Obligatoria de los Tribunales Internacionales de Derechos Humanos", in El Sistema Interamericano de Protección de los Derechos Humanos en el Umbral del Siglo XXI-Memoria del Seminario (nov. 1999), vol. I, $2^{a}$ ed., San José de Costa Rica, Corte Interamericana de Derechos Humanos, 2003, pp. 3-68.

15 Vide Corte IDH, Direito à Informação sobre a Assistência Consular no âmbito das Garantias do Devido Processo Legal, 1999, Voto concordante do juiz A. A. CANÇADO TRINDADE no parecer n. 16, par. 3-4.

16 Para mais detalhes, vide A. A. CANÇADO TRINDADE, A Humanização do Direito Internacional, op. cit., pp. 129-156; A. A. CANÇADO TRINDADE, El Derecho Internacional de los Derechos Humanos en el siglo XXI, op. cit., pp. 319-376; A. A. CANÇADO TRINDADE, El ejercicio de la función judicial internacional - Memorias de la Corte Interamericana de Derechos Humanos, op. cit., pp. 109-126; A. A. CANCADO TRINDADE, Évolution du droit international au droit des gens - l'accès des individus à la justice internationale: le regard d'un juge, op. cit., pp. 26-61; A. A. CANÇADO TRINDADE, O Direito Internacional em um mundo em transformação, Rio de Janeiro, ed. Renovar, 2002, pp. 550-584.

17 A. A. CANCADO TRINDADE, Tratado de Direito Internacional dos Direitos Humanos, tome III, Porto
Alegre, Brésil, éd. S. A. Fabris, 2002, p. 524, § 187; A. A. CANCADO TRINDADE, Évolution du droit international au droit des gens - l'accès des individus à la justice internationale, le regard d'un juge, op. cit., p. 117; A. A. CANCADO TRINDADE, "El Nuevo Reglamento de la Corte Interamericana de Derechos Humanos (2000) y Su Proyección Hacia el Futuro: La Emancipación del Ser Humano como Sujeto del Derecho Internacional de los Derechos Humanos", 28 Curso de Derecho Internacional, Comitê Jurídico Interamericano - OAS (2001), pp. 33 92; A. A. CANÇADO TRINDADE, El Acceso Directo del Individuo a los Tribunales Internacionales de Derechos Humanos, Bilbao, Universidad de Deusto, 2001, pp. 9 104; A. A. CANÇADO TRINDADE, "Vers la consolidation de la capacité juridique internationale des pétitionnaires dans le système interaméricain des droits de la personne", 14 Revue québécoise de Droit International, 2001, n. 2, pp. 207-239; A. A. CANÇADO TRINDADE, "A Emancipação do Ser Humano como Sujeito do Direito Internacional e os Limites da Razão de Estado”, in $6 / 7$ Revista da Faculdade de Direito da Universidade do Estado do Rio de Janeiro (1998-1999), pp. 427-428 e 432 433; A. A. CANÇADO TRINDADE, "El Derecho de Petición Individual ante la Jurisdicción Internacional", 48 Revista de la Facultad de Derecho de México, UNAM, 1998, pp. 131-151.

18 A. A. CANÇADO TRINDADE, Tratado de Direito Internacional dos Direitos Humanos, op. cit., pp. 523524; A. A. CANCADO TRINDADE, Évolution du droit international au droit des gens - l'accès des individus à la justice internationale : le regard d'un juge, op. cit., pp. 116-119.

19 Segundo Cançado Trindade, "without the right of individual petition, and the consequent Access to justice at international level, the rights set forth in human rights treaties would be reduced to a little more than dead letter" (p. 237). Vide também Corte IDH, Castillo Petruzzi e Outros versus Peru (Objeções Preliminares), julgamento de 04.09.1998, série C, n. 41, Opinião concorrente do juiz A. A. CANÇADO TRINDADE, p. 62, par. 35; A. A. CANÇADO TRINDADE, A Humanização do Direito Internacional, op. cit., pp. 109-118.

20 Vide A. A. CANÇADO TRINDADE, "Complementarity between State Responsibility and Individual Responsibility for Grave Violations of Human Rights: The Crime of State Revisited", in International Responsibility Today - Essays in Memory of O. Schachter (ed. M. Ragazzi), Leiden, M. Nijhoff, 2005, pp. 253-269.

21 A. A. CANÇADOTRINDADE, A Humanização do Direito Internacional, op. cit., pp. 281-352; A. A. CANÇADO TRINDADE, El Derecho Internacional de los Derechos Humanos en el siglo XXI, op. cit., pp. 185-267; A. A. CANÇADO TRINDADE, El ejercicio de la función judicial internacional - 
Memorias de la Corte Interamericana de Derechos Humanos, op. cit., pp. 185-196.

22 A. A. CANÇADO TRINDADE, A Humanização do Direito Internacional, op. cit., pp. 226-277; A. A. CANÇADO TRINDADE, $O$ Direito Internacional em um mundo em transformação, op. cit., pp. 749-789.

23 Vide A. A. CANÇADO TRINDADE, "The Relevance of International Adjudication Revisited: Reflections on the Need and Quest for International Compulsory Jurisdiction", in Towards World Constitutionalism - Issues in the Legal Ordering of the World Community (eds. R. St. J. Macdonald e D.M. Johnston), Leiden, Nijhoff, 2005, pp. 515-542.

24 Vide A. A. CANÇADO TRINDADE, "The Merits of Coordination of International Courts on Human Rights", 2 Journal of International Criminal Justice, Oxford, 2004, pp. 309-312; A. A. CANÇADO TRINDADE, "La perspective transatlantique: La contribution de l'œuvre des Cours internationales des droits de l'homme au développement du droit public international", in $\mathrm{La}$ Convention européenne des droits de l'homme à 50 ans - Bulletin d'information sur les droits de l'homme, n. 50 (numéro spécial), Strasbourg, Conseil de l'Europe, 2000, pp. 8-9

25 C.I.J., acórdão de 3 de fevereiro de 2012, Immunités juridictionnelles de l'État (Allemagne c. Italie; Grèce (Intervenant)), opinião dissidente do juiz A. A. CANÇADO TRINDADE, p. 3, par. 2 .

26 C.I.J., acórdão de 3 de fevereiro de 2012 , Immunités juridictionnelles de l'État (Allemagne c. Italie; Grèce (Intervenant)), opinião dissidente do juiz A. A. CANÇADO TRINDADE, p. 82, par. 289.

27 C.I.J., acórdão de 3 de fevereiro de 2012, Immunités juridictionnelles de l'État (Allemagne c. Italie; Grèce (Intervenant)), opinião dissidente do juiz A. A. CANÇADO TRINDADE, p. 84, par. 299.

28 Vide CORTEN (O.), "La thèse de la déformalisation du droit international et ses limites : l'exemple de la jurisprudence de la Cour Internationale de Justice", L'Observateur des Nations Unies, 2011-I, vol. 30, pp. 75-98

29 Nesse sentido, afirma o juiz M. Bennouna que "le monde du juriste n'est pas un monde aseptisé, comme le serait celui d'un pur mathématicien, opérant dans sa tour d'ivoire, il est en prise avec les réalités sociales en amont et en aval de la norme". Continua afirmando que o papel da Corte Internacional de Justiça “n'est pas seulement de développer une argumentation formelle mais de rendre la justice, en veillant à ce que ses arrêts soient perçus comme tels" (BENNOUNA (M.), "Le formalisme juridique: pour quoi faire ?", L'Observateur des Nations Unies, 2011-I, vol. 30, pp. 8 e 9).

30 Vide igualmente CANÇADO TRINDADE (A. A.), Direito das Organizações Internacionais, $4^{\mathrm{a}}$ edição, Ed. Del Rey, Belo Horizonte, 2009, p. XXV.

\section{Paula Wojcikiewicz Almeida}

Praia de Botafogo, n. 190, $13^{\circ}$ andar Botafogo - 22250-040 Rio de Janeiro - RJ - Brasil paula.almeidalafgr.br
DOUTORA EM DIREITO INTERNACIONAL E EUROPEU PELA UNIVERSITÉ DE PARIS 1 Panthéon-SORBOnNe (SUMma CUM LAUde)

DOUTORA EM DIREITO INTERNACIONAL E INTEGRAC̦ÃO ECONÔMICA PELA UERJ

Mestre em Direito Público Internacional E EUROPEU PELA UNIVERSITÉ DE PARIS XI

Professora de Direito InTERnacional da FGV DiREITO RIO E PESQUISADORA dO CENTRO DE JUSTICA E SOCIEDADE DA FGV DIREITO RIO 